\title{
PEMIKIRAN POLITIK ISLAM TUAN GURU KYAI HAJI MUHAMMAD ZAINUDDIN ABDUL MAJID
}

\author{
Chaidir Amry, Zakaria Ansori \\ Universitas Islam Negeri Mataramn \\ Universitas Islam Negeri Syarif Hidayatullah Jakarta \\ zakariaansori@uinmataram.ac.id
}

\begin{abstract}
Abstrak
Semangat keagamaan diwujudkan dengan bagitu banyak varian, lebih-lebih jika kepercayaan akan agama sudah mengakar di dasar hati. Agama menawarkan suatu cara pandang hidup yang mampu meng-cover setiap tindakan, perbuatan yang mengarah pada pembentukan manusia seutuhnya. Islam demikian juga, membuat aturan baku untuk setiap umatnya-yang dalam hal ini mengatur setiap sisi-sisi kehidupan baik dalam setiap aspeknya, baik sosial, budaya, hukum dan model khilafah (sebagaimana yang telah dicontohkan oleh Nabi saw). Agama dan pemerintahan (politik) dua sisi yang dianggap bersebrangan. "agama" sebagai dasar berpolitik, dalam melestarikan keyakinan yang anut terkadang mengalami hambatan, karena pemerintah menggangap sebagai salah batu sandungan yang mampu menggeser ketahanan pemerintahan. Sebagaiman aktivitas politik Tuan Guru Kyai Haji Muhammad Zainuddin Abdul Majid akan terlihat jelas pasca kemerdekan dengan mengikuti partai politik dan menentukan arah bangsa Indonesia dengan mewakili kaum muslimin di Pulau Lombok. Karir politik Tuan Guru Kyai Haji Muhammad Zainuddin Abdul Majid dimulai sejak diangkat sebagai Konsulat Nahdlatul Ulama (NU) Sunda Kecil pada tahun 1950. Pada tahun 1952 beliau diangkat menjadi Ketua Badan Penasihat Partai Masyumi untuk daerah Lombok, ini disebabkan pada waktu itu Nahdlatul Ulama dan beberapa ormas lainnya tergabung dalam partai Masyumi.
\end{abstract}

Kata Kunci: Pemikiran, Politik Islam, dan Tuan Guru. 


\section{A. Latar Belakang}

Politik Islam sudah mulai bermunculan pada pra-kemerdekaan Indonesia. Islam dianggap sebagai pembawa kesadaran nasionalisme untuk melawan penjajah. Yakni para kyai dan ulama pada awal dekade 1900-an menyerukan pencerahan dan pencerdasan anak bangsa (masyarakat pribumi). ${ }^{1} \quad$ Ini dibuktikan dengan berdirinya beberapa organisasi yang berbasis Islam seperti Sarekat Dagang Islam (SDI) pada tahun 1905 dan Sarekat Islam (SI) pada tahun 1912. Umat Islam pasca-kemerdekaan pernah tergabung dalam satu wadah politik yaitu partai Masyumi yang disepakati setelah Kongres Umat Islam Indonesia di Yogyakarta sebagai satusatunya partai politik umat Islam.

Dikeluarkannya Dekrit 5 Juli 1959 oleh presiden Soekarno membuat beberapa pemimpin dari partai Masyumi kecewa dengan presiden Soekarno dan dianggap sebagai otoriter hingga melakukan perlawanan. Akibatnya, beberapa dari

${ }^{1}$ Syarifuddin Jurdi, Pemikiran Politik Islam Di Indonesia: Pertautan Negara, Khilafah, Masyarakat Madani Dan Demokrasi (Yogyakqarta: Pustaka Pelajar, 2008), hal 152 pemimpin tersebut ditangkap dan partai Masyumi menjadi partai terlarang pada 30 september 1960.

Pada masa Orde Baru, kalangan Islam kesulitan melakukan artikulasi politik meski telah berkerjasama dalam menumbangkan pemerintahan Orde Lama. Rezim Orde Baru tidak hanya menolak merehabilitas partai Masyumi tapi juga dengan tegas menolak kembali pemimpin-pemimpin partai tersebut dalam kehidupan politik. Sampai akhirnya negara menyederhanakan partai politik. Partai-partai Islam tergabung dalam Partai Persatuan Pembangunan (PPP) sedangkan, untuk yang nasionalis dan non-Islam tergabung dalam Partai Demokrasi Indonesia (PDI). Penyerdehanaan ini dilakukan agar mengurangi konflik dan aktifitas partai mudah dikontrol oleh negara. ${ }^{2}$

Karir politik Tuan Guru Kyai Haji Muhammad Zainuddin Abdul Majid dimulai sejak diangkat sebagai Konsulat Nahdlatul Ulama (NU) Sunda Kecil pada tahun 1950. Pada tahun 1952 beliau diangkat menjadi Ketua ${ }^{2}$ Ibid., hal 174 
Komunike, Volume XI, No. 1, Juni 2019

Badan Penasihat Partai Masyumi untuk daerah Lombok, ini disebabkan pada waktu itu Nahdlatul Ulama dan beberapa ormas lainnya tergabung dalam partai Masyumi. ${ }^{3}$

Tuan Guru Kyai Haji Muhammad Zainuddin Abdul Majid mendirikan organisasi Nahdlatul Wathan (NW) pada tahun 1953. Nahdlatul Wathan menganut "politik bebas" dari tahun 1953-1955. Namun, pada tahun 1955 memilih untuk berafiliasi dengan partai Masyumi sehingga Tuan Guru Kyai Haji Muhammad Zainuddin Abdul Majid diangkat menjadi anggota Konstituante periode $1955-1959$, hasil Pemilihan Umum (Pemilu) pertama pada tahun 1955. Partai Masyumi dikucilkan oleh DPRGR pada bulan April 1960 dan diperintahkan untuk membubarkan diri empat bulan kemudian, Tuan Guru Kyai Haji Muhammad Zainuddin Abdul Majid merubah haluan politiknya ke partai Golongan Karya (Golkar) pada 28 September 1970. Alasan berafiliasinya dengan Golkar karena pemerintah

${ }^{3}$ Mohammad Noor, dkk, Visi Kebangsaan Religus; Refleksi Pemikiran dan Perjuangan TGKH Muhammad Zainuddin Abdul Majid 1904-1997 (Jakarta: Logos Wacana Ilmu, 2004), hal 245
Orde Baru telah melakukan represi politik terhadap Ormas-Ormas Islam untuk memilih Golkar.

Dalam Pemilihan Umum tahun 1971 dan 1977, Tuan Guru Kyai Haji Muhammad Zainuddin Abdul Majid terpilih menjadi anggota Majelis Permusyawaratan Rakyat (MPR) RI dari partai Golkar. Kemudian terpilih menjadi anggota MPR-RI Fraksi Utusan Daerah pada tahun 1982.

Politik Nahdlatul Wathan kepada Golkar merupakan embrio bagi konflik internal organisasi tersebut. Sebab, sebagian kader-kader Nahdlatul Wathan lebih memilih garis politiknya dengan berafiliasi dengan Partai Pembangunan Persatuan (PPP) yang notabene merupakan partai Islam. Namun, dipertengahan rezim Orde Baru Tuan Guru Kyai Haji Muhammad Zainuddin Abdul Majid tak lagi memobilisator kemenangan Golkar di Nusa Tenggara Barat (NTB) dan lebih condong kepada PPP meski beliau masih berafiliasi dengan Golkar. Menurutnya "politik asal politik yang lama kelamaan menjadi licik" ${ }^{4}$. Seperti

${ }^{4}$ Mohammad Noor, dkk, Visi Kebangsaan ..., 
rezim Orde Baru yang sangat terkenal sebagai rezim diktator, disebutkan juga dalam syairnya.

Kalau orang berjiwa basi Hanya mengejar bayangan kursi Tidak peduli tuntunan ilahi Selalu menendang ayat al-kursi ${ }^{5}$

Tuan Guru Kyai Haji Muhammad Zainuddin Abdul Majid adalah ulama sekaligus politikus. Hubungan antara agama dan politik tidak terlepas dari semangat beliau dalam melakukan dakwah untuk menyebarkan agama Islam di Pulau Lombok. Pengertian dakwah yang lebih luas bahwa penyebaran agama Islam bisa dilaksanakan melalui jalur-jalur politik sebagai metode dakwah. Pandangan Tuan Guru Kyai Haji Muhammad Zainuddin Abdul Majid tentang agama tergambar pada syairnya yang berbunyi;

Agama bukanlah sekedar ibadah Puasa, sembayang di atas sajadah Tapi agama mencakup aqidah Mencakup syariah mencakup hukumah. ${ }^{6}$

hal 244

${ }^{5}$ Tuan Guru Haji Muhammad Zainuddin Abdul Majid, Wasiat Renungan Masa Pengalaman Baru, (Lombok Timur: Pengurus Besar Nahdlatul Wathan, 2002), hal. 52

6 Ibid., hal. 37 .
Syair di atas menjelaskan bahwa agama tidak sekedar urusan ibadah yakni melaksanakan perintahnya dan menjauhi larangan Allah SWT. Akan tetapi agama lebih dalam lagi tentang Aqidah yaitu keyakinan, dalam sebuah keyakinan teradapat hukum-hukum. Dengan demikan Tuan Guru Kyai Haji Muhammad Zainuddin Abdul Majid menggunakan politik sebagai jalan untuk menyebarkan agama Islam di Pulau Lombok.

Pemikiran keagamaan Tuan Guru Kyai Haji Muhammad Zainuddin Abdul Majid beraliran Alussunnah wal Jama'ah. Penjelasan ini tedapat pada asas Nahdlatul Wathan yaitu Islam Ahlussunnah Wal Jama'ah ala Madzhabil Imam Asysafi'i r.a7. Dengan demikian maka dalam asas tersebut telah tercermin jiwa perjuangan Nahdlatul Wathan yaitu Islam, Ahlussunnah Wal Jamaah, Madzahab Imam Syafi'i r.a.

Aktivitas politik Tuan Guru Kyai Haji Muhammad Zainuddin Abdul Majid akan terlihat jelas pasca

${ }^{7}$ Afifuddin Adnan, Diktat Pelajaran Ke-NWan, (Pancor: Biro Dakwah Yayasan Pendidikan Hamzanwadi, 1983), hal. 10. 
Komunike, Volume XI, No. 1, Juni 2019

kemerdekan dengan mengikuti partai politik dan menentukan arah bangsa Indonesia dengan mewakili kaum muslimin Pulau Lombok.

\section{B. Politik Islam}

Islam dan politik mempunyai titik singgung erat, bila keduanya dipahami sebagai sarana menata kebutuhan hidup rnanusia secara menyeluruh. Islam tidak hanya dijadikan kedok untuk mencapai kepercayaan dan pengaruh dari masyarakat semata. Politik juga tidak hanya dipahami sekadar sebagai sarana menduduki posisi dan otoritas formal dalam struktur kekuasaan. Syari'ah Islam mencakup juga tatanan mengenai kehidupan berbangsa dan bernegara. Kehidupan berbangsa, misalnya tergambar dalam tatanan syari'at tentang berkomunitas (mu'asyarah) antar sesama manusia. Sedangkan mengenai kehidupan bernegara, banyak disinggung dalam ajaran fiqih siyasah dan sejarah Khilafah alRasyidah. ${ }^{8}$

${ }^{8}$ KH MA Sahal Mahfudh, Nuansa Fiqih Sosial, (Yogyakarta: LKiS, 2004), hal. 202.
Pada tingkat global, kehidupan sosial, politik, ekonomi, dan budaya hampir dikuasai oleh kaum barat dengan budaya yang bertentangan dengan nilai-nilai Islam. Sehingga sebagian umat Islam menggunakan nilai-nilai Islam dalam acuan berpolitik, baik secara simbolik atau pun substantif untuk membentuk suatu pemerintahan Islam, terutama kalangan yang konsen dengan perjuangan untuk menyatukan politik dan agama agar dapat mengangkat harkat dan martabat umat Islam, khusunya untuk melindnugi diri dari hegemoni barat. ${ }^{9}$ Aktivitas politik Islam menimbulkan beberepa gerakan, baik yang berjuang secara struktural (dalam pemerintahan), Perjuangan politik Islam melalui struktural adalah upayaupaya menekankan melalui penetapan sistem nasional maupun kebijakan publik yang Islami. Selain itu, sebagai fungsi kontrol terhadap pemerintah, kontrol terhadap pemerintah sudah diungkapkan oleh semua ulama dan intelektual muslim, sebagai manifestasi dan konsep amr ma'ruf 93

${ }^{9}$ Syarifuddin Jurdi, Pemikiran Politik..., hal. 
nahi munkar yang merupakan terdiri dari (a) tradisionalis, yakni kewajiban bagi setiap muslim, mereka yang tetap mempertahankan termasuk terhadap pemerintah. ${ }^{10}$ dan tradisi praktik dan pemikiran politik berjuang secara kultural (di luar Islam klasik/pertengahan, seperti pemerintahan), yakni politik Islam Rasyid Ridha, dan (b) fundamentalis, yang diwujudkan melalui upaya yakni mereka yang ingin melakukan perubahan kesadaran tingkah laku reformasi sistem sosial dengan umat Islam tanpa keterlibatan negara kembali kepada Islam secara total dan dan tanpa perubahan sistem nasional menolak sistem yang dibuat manusia, menjadi sistem Islami. Aktivitas politik seperti Sayyid Qutub dan Abu al-A'la Islam kultural yaitu mewujudkan al-Maududi dan Hasan Tarabi. Kedua, dirinya secara subtantif dalam adalah kelompok modernis, yang lembaga-lembaga kebudayaan dan berpendapat bahwa Islam mengatur peradaban Islam. singkatnya adalah masalah keduniaan (kemasyarakatan) berjuang untuk menyebarkan Islam hanya secara dasar-dasarnya saja, melalui dakwah, pendidikan, seni, dan adapun secara tehnis bisa mengadopsi sebagainya.

Di kalangan ulama dan sistem lain, yang dalam hal ini adalah intelektual muslim di dunia terdapat sistem barat yang sudah menunjukkan tiga pandangan hubungan antara kelebihannya. Di antara tokoh ajaran islam dengan masalah kelompok ini adalah Muhammad kenegaraan. Pertama, adalah Abduh, Husein Haikal, dan Muhammad kelompok konservatif, yang tetap Asad. Ketiga, yang memisahkan antara mempertahankan integritas antara Islam dengan negara, karena menurut Islam dan negara, karena menurut mereka, Islam telah lengkap mengatur sistem kemasyarakatan. Kelompok ini

kelompok ini Islam, seperti agamaagama lainnya, tidak mengatur masalah keduniaan, sebagaimana praktik kenegaraan yang terdapat di

${ }^{10}$ Masykuri Abdillah "Negara Ideal Menurut Islam dan Implementasinya Pada Masa Kini” dalam Komaruddin Hidayat (ed), Islam, Negara, \& Civil Society, (Jakarta: Paramadina, 2005). Hal. 88. 
barat. Di antara tokoh aliran ini adalah Ali Abdurraziq dan Thaha Husein. ${ }^{11}$

\section{Negara dan Islam}

Dalam al-Qur'an maupun hadis tidak ditemukan istilah atau konsep tentang negara. Namun, konsep negara bukan tidak ada sama sekali dalam Islam, karena secara substantif terdapat sejumlah ayat al-Qur'an dan hadis menunjukkan adanya pemerintahan pada umat Islam. Sedangkan, negara Islam itu sendiri baru muncul pada pertengahan abad ke-20, yang dipahami sebagai negara yang melaksanakan etika dan syariah Islam. Di dalam al-Qur'an terdapat pirinsip-prinsip atau nilai-nilai yang harus dipraktikkan dalam kehidupan bermasyarakat dan bernegara; kejujuran dan tanggungjawab, keadilan, persaudaraan, menghargai kemajemukkan atau pluralisme, persamaan, permusyarawatan, mendahulukan perdamaian, dan kontrol. ${ }^{12}$

${ }^{11}$ Masykuri Abdillah, Demokrasi Di Persimpangan Makna; Respons Intelektual Muslim Indonesia Terhadap Konsep Demokrasi (19661993), terj. Drs. Wahib wahab, MA. ( Yogyakarta: Tiara Wacana Yogya, 2004), cet. Ke-2, hal. 57 ${ }^{12}$ Masykuri Abdillah "Negara Ideal Menurut..., hal. 74
Di dalam politik, banyak pemikir Islam ingin Islam menjadi sistem hukum maupun sebagai sistem pemerintahan, bahkan ada gagasan yang menginginkan membentuk negara Islam, mereka yang menginginkan membentuk negara Islam sebab melihat negara Madinah sebagai prototipe negara Islam yang ideal.

Gagasan negara Islam penuh utopia karena menawarkan konteks masa lalu untuk masa kini yang penuh dengan paradoks dan dialetika. Gagasan ini menimbulkan protes dari kalangan internal Islam, mereka berpendapat, penyatuan agama dan politik akan mencemarkan makna etis dan kesucian agama, karena politik cenderung kooperatif, manipulatif dan palsu. Jika dipadukan dengan politik, agama justru menjadi sangat bias kepentingan. Disini kita bisa kutip pernyataan Nurcholis Madjid:

$$
\text { “konsep negara Islam }
$$
merupakan distorsi atas keterkaitan yang proporsional antara negara dan agama. Negara adalah aspek kehidupan profane berdimensi 
rasional dan kolektif, sementara dari tipologi ini adalah Ali Abd al-Raziq, agama adalah aspek kehidupan lain, A. Luthfi Sayyid, dan di Indonesia yang dimensinya adalah spiritual dan Soekarno. ${ }^{15}$ Ketiga, Tipologi Moderat. individual" ${ }^{13}$

Di kalangan pemikir Islam terdapat tiga tipologi terkait hubungan Islam dan negara: Pertama, Tipologi hubungan organik dan bentuk pemerintahan teo-demokrasi. Tipologi ini melihat bahawa Islam adalah agama sekaligus negara. Hubungan Islam dan negara betul-betul organik di mana negara berdasarkan syariah Islam dengan ulama sebagai penasihat resmi eksekutif atau bahkan pemegang kekuasan tertinggi. Pemikir dari tipologi ini antara lain, Rasyid Ridha, Sayyid Qutub, Abu al-A'la al-Maududi, dan di indonesia Muhammad Natsir. ${ }^{14}$ Kedua, Tipologi sekuler. Islam adalah agama murni bukan negara. Negara tidak harus diatur agama, begitupun sebaliknya negara juga tidak boleh mengintervensi urusan agama. Pemikir

\footnotetext{
${ }^{13}$ Nurcholish Madjid, Islam, Kemoderenan, dan Keindonesiaan, (Bandung: Mizan, 1994), cet. Ke-6, Hal. 61

${ }^{14}$ Sukron Kamil, Pemikiran Politik Islam Tematik; Agama Dan Negara, Demokrasi, civil Society, Syariah dan HAM, Fundamentalisisme, dan Antikorupsi, (Jakarta: Kencana Prenada Media Gorup), hal. 21.
} Tipologi ini menolak klaim ekstream bahwa Islam adalah agama yang lengkap yang mengatur semua urusan termasuk politik. Menurut tipologi ini, kendati Islam tidak menunjukan prefensinya pada sistem politik tertentu, tetapi dalam Islam terdapat prinsip-prinsip moral dan etika bagi kehidupan bermasyarakat dan bernegara, yang untuk pelaksanaannya umat Islam bebas memilih sistem manapun yang terbaik. Pemikir yang termasuk tipoogi ini adalah Muhammad Husein Haikal, Muhammad Abduh, Fazlurrahman, Moahmed Arkoun, dan di Indonesia Nurcholish Madjid. ${ }^{16}$

\section{Biografi Tuan Guru Kyai Haji Muhammad Zainuddin Abdul Majid}

Tuan Guru Kyai Haji Muhammad Zainuddin Abdul Majid memiliki nama kecil Muhammad Saggaf lahir di Kampung Bermi, Desa Pancor, Lombok

\footnotetext{
${ }^{15}$ Ibid., hal. 26

${ }^{16}$ Ibid., Hal 31.
} 
Komunike, Volume XI, No. 1, Juni 2019

Timur pada hari rabu 17 rabiul awal 1326 (1904 M). Dari pasangan Tuan Guru Haji Abdul Madjid dan $\mathrm{Hj}$. Halimatussa'diyah. Anak bungsu dari enam bersaudara, yaitu, Siti Sarbini, Siti Cilah, Hajah Saudah, Haji Muhammad Shabur dan Hajah Masyitah. ${ }^{17}$

Ketika Muhammad Saggaf dan ayahnya pergi menunaikan ibadah haji ke Mekah, ayahnya bertemu dengan seorang ulama yang memiliki kepribadian dan akhlak mulia yaitu Syaikh Muhammad Zainuddin Serawak. Sebab ketertarikkan inilah Muhammad Saggaf diganti namanya menjadi Zainuddin oleh ayahnya sendiri setelah menunaikan ibadah haji. $^{18}$

Tuan Guru Kyai Haji Muhammad Zainuddin Abdul Majid memulai pendidikan di dalam keluarga, belajar mengaji dan berbagai ilmu agama diajarkan langsung oleh ayahnya, dimulai sejak berumur lima tahun sampai sembilan tahun. Beliau memasuki pendidikan formal pada

${ }^{17}$ Mohammad Noor, dkk, Visi Kebangsaan ..., hal 123

${ }^{18}$ Ibid. sebuah sekolah umum yang disebut Sekolah Rakyat Negara (Sekolah Gubermen), di sekolah tersebut beliau belajar selama empat tahun. ${ }^{19}$

Selain pendidikan formal, beliau juga diserahkan ayahnya untuk belajar ilmu agama kepada Tuan Guru lokal saat itu, antara lain, Tuan Guru Syarafuddin dan Tuan Guru Haji Muhammad Sa'id dari Pancor, dan Tuan Guru Abdullah Bin Amaq Dulaji dari Kelayu Lombok Timur. ${ }^{20}$ pola belajar yang dilakukan oleh Tuan Guru lokal ini masih sangat tradisional (konservatif), yang dikenal dengan pola belajar halaqah, yaitu muridmurid duduk bersila di atas tikar dan mendengarkan gurunya membaca kitab yang sedang dipelajari. Setelah itu, murid-murid secara bergantian membaca. ${ }^{21}$

Pada saat itu murid-murid yang mengaji di rumah seorang Tuan Guru tidak dipungut bayaran. Sebagai gantinya mereka diharuskan bekerja disawah Tuan Guru tersebut.

\footnotetext{
${ }^{19}$ Mohammad Noor, dkk, Visi Kebangsaan ..., hal. 134 ${ }^{20}$ Ibid.

${ }^{21}$ Mahmud Yunus, Sejarah Pendidikan Islam di Indonesia, (Jakarta: Hidakarya Agung, 1996), hal. $341-342$.
} 
Komunike, Volume XI, No. 1, Juni 2019

Sedangkan, Muhammad Saggaf, Syaikh Marzuqi seorang ulama karena keinginan kuat ayahnya agar keturunan Arab kelahiran Palembang beliau menjadi murid yang pandai, yang mengajar di Masjidil Haram. Tuan ayahnya sanggup membayar dengan Guru Haji Abdul Majid menyerahkan 200 ikat padi setahun (sekitar dua ton anaknya kepada Syaikh Marzuqi untuk padi/gabah), sebagai ganti kewajiban menuntut ilmu.

bekerja di sawah. Dengan kesediaan Setelah ayahnya pulang ke tersebut, ayahnya bermaksud agar Lombok, Tuan Guru Kyai Haji kegiatan proses belajarnya tidak Muhammad Zainuddin Abdul Majid terganggu dan tetap konsentrasi berhenti belajar mengaji kepada terhadap apa yang dipelajarinya. ${ }^{22}$ Syaikh Marzuqi disebabkan tidak Kondisi ekonomi keluarga TGH. Abdul nyaman dan merasa tidak mengalami Madjid yang cukup baik, membuat perkembangan selama menuntut ilmu beliau termasuk beruntung bisa di sana. Namun, belum sempat mengenyam pendidikan formal. Satu mencari guru baru, terjadi perang dari 845 anak yang bisa bersekolah di saudara di Saudi Arabia antara Fraksi seluruh Lombok saat itu. ${ }^{23}$

Wahabi melawan kekuasaan Syarif

Pada umur tujuh belas tahun, Husein. Peperangan ini menyebabkan Tuan Guru Kyai Haji Muhammad Masjidil Haram dalam keadaan sepi Zainuddin Abdul Majid diajak oleh tanpa ada aktivitas pengajian. Pada ayahnya untuk menunaikan ibadah haji saat itu beliau bersama temannya, sekaligus untuk menuntut ilmu agama Sayyid Syeikh Muhsin al-Musawa di Mekah. Setelah beberapa hari sempat belajar sastra dengan musim haji selesai, Tuan Guru Haji spesifikasi syair-syair Arab kepada Abdul Majid mencari guru untuk Syaikh Muhammad Amin al-Kutbi. anaknya hingga bertemulah dengan Awal kedatangan Tuan Guru Kyai Haji ..., hal. 135

${ }^{22}$ Mohammad Noor, dkk, Visi Kebangsaan Muhammad Zainuddin Abdul Majid juga ditandai dengan runtuhnya

${ }^{23}$ Alfons Van Der Kraan, Lombok: Penaklukan, Penjajahan, dan Keterbelakangan 1870-1940 (Yogyakarta: Lengge, 2009), hal. 207 
Komunike, Volume XI, No. 1, Juni 2019

dideklarasikannya negara Republik membeberkan, pada tahun 1912, salah Turki oleh Kemal Attaturk. satu priode puncak dalam sejarah

Dua tahun setelah terjadinya madrasah ini. Dari jumlah total 537 perang saudara Tuan Guru Kyai Haji murid, komposisi mereka dari negeri Muhammad Zainuddin Abdul Majid asal sebagai berikut: Turki 13 orang, bertemu dengan Haji Mawardi dari Hijaz 4, Yaman 6, Indonesia 178, Irak 8, Jakarta. Dari perkenalan itu, Tuan Guru Kyai Haji Muhammad Zainuddin Abdul Majid diajak untuk menuntut ilmu di Madrasah al-Shaulatiyah. Madrasah yang didirikan pada tahun $1219 \mathrm{H}$, oleh ulama besar imigran India yaitu Syaikh Rahmatullah Ibnu Khalil al-Hindi alDahlawi.

Madrasah al-Shaulatiyah adalah madrasah pertama sebagai permulaan sejarah baru dalam pendidikan di Arab Saudi. Madrasah ini sangat legendaris dan telah menghasilkan ulama-ulama besar dunia. Kiyai Haji Hasyim Asyari (pendiri NU), Kiyai Haji Ahmad Dahlan (pendiri Muhammadiyah), dan ratusan ulama di wilayah Asia Tenggara. Madrasah ini didirikan Syeikh Muhammad Rahmatullah yang berasal dari India. Penulis anonim asal India, seperti dikutip Abdul Latif Abdallah Dohaish dalam History of Education in the Hijaz up to 1925

Syria 3, India 74, Afghanistan 4, dan Bukhara 22. Laporan tahunan alShaulatiyyah (1913) mengemukakan data yang lebih akurat. Komposisi murid Hijaz 186 orang, India 108, Indonesia 156, Bukhara 23, Afghanistan 18, Iraq 6, Iran 6, Yaman 8, dan Hadramaut 7 Orang. Melihat angka-angka ini, bisa dipahami kalau Faisal Abd Allah al-Aqawi, dalam At Ta'lim al-Ahli li al-Banin Makkah alMukarramah (1404 H/1984 M), menyatakan al-Shaulatiyyah merupakan kancah murid-murid Jawi. ${ }^{24}$

Tuan Guru Kyai Haji Muhammad Zainuddin Abdul Majid dengan diantar oleh Haji Mawardi langsung bertemu dengan mudir Madrasah al-Shaulatiyah tersebut yaitu Syeikh Salim Rahmatullah yang merupakan cucu

\footnotetext{
${ }^{24}$ Azyumardi Azra, Renaisanse Islam Asia Tenggara, (Bandung: Remaja Rosda Karya, 1999), hal. 155 .
} 
Komunike, Volume XI, No. 1, Juni 2019

dari pendiri Madrasah al-Shaulatiyah. Seorang murid baru harus mengikuti tes masuk untuk menentukkan kelas. Tuan Guru Kyai Haji Muhammad Zainuddin Abdul Majid diuji langsung oleh Syeikh Salim Rahmatullah dan Syeikh Hasan Muhammad alMasysyath. Penguji menentukkan beliau masuk di kelas III. Tuan Guru Kyai Haji Muhammad Zainuddin Abdul Majid menolak dan memaksa untuk masuk di kelas II, dengan alasan ingin mendalami ilmu nahwu-sharaf.

Tuan Guru Kyai Haji Muhammad Zainuddin Abdul Majid selalu memanfaatkan waktu untuk belajar. Seperti yang diungkapkan oleh murid beliau yaitu, Tuan Guru Haji Yusuf Makmun sebagai berikut:

"Selain di Shaulatiyah, Tuan Guru Kyai Haji Muhammad Zainuddin Abdul Majid juga mencari guru di luar (mengaji luar). Jadi sepulang dari madrasah beliau mengaji di rumahrumah ulama, ini selalu dilakukan sampai beliau lulus di Madrasah alShaulatiyah, sehingga beliau memiliki banyak guru. Guru-gurunya yang dibanggakan berjumlah 53 orang". 25

Tuan Guru Kyai Haji Muhammad Zainuddin Abdul Majid berhasil menyelesaikan studinya dalam kurun waktu enam tahun. Padahal lama belajar normal adalah selama sembilan tahun. Dari kelas II, beliau loncat ke kelas IV, tahun berikutnya ke kelas VI, pada tahun-tahun berikutnya secara berturut-turut naik ke kelas VII, VIII, IX. Selama mengikuti pelajaran, beliau tercatat sebagai murid berprestasi. Beliau juga sering ditunjuk untuk mewakili di berbagai acara seperti saat ada kunjungan pengawas madrasah dari kerajaan saudi. ${ }^{26}$

Dengan prestasi akademik dan keceradasan yang sangat tinggi, Tuan Guru Kyai Haji Muhammad Zainuddin Abdul Majid berhasil lulus dari Madrasah al-Shaulatiyah dengan predikat mumtaz (summa cumlaude). Guru-guru di Madrasah al-Shaulatiyah merasa kesulitan memberikan nilai kepada Tuan Guru Kyai Haji

${ }^{25}$ Yusuf Makmun, wawancara, Pancor, 5 Desember 2017

${ }^{26}$ Masnun, Tuan Guru KH Muhammad Zainuddin Abdul Majid; Gagasan dan Gerakan Pembaharuan Islam Di Nusa Tenggara Barat (Jakarta: Pustaka al-Miqdad, 2007), hal 19 
Komunike, Volume XI, No. 1, Juni 2019

Muhammad Zainuddin Abdul Majid, Lombok".28 Lebih jauh, Dr. Tohri seperti ungkapan Ustadz Mursyidin, menjelaskan:

"para guru di Madrasah al- "guru-guru di Madrasah Shaulatiyah merasa kesulitan Shaulatiyah memarahi murid-murid memberikan nilai, sebab nilai Indonesia yang tidak membantu Zainuddin berada di atas rata-rata, memperjuangkan kemerdekaan tanah sedangkan pemberian nilai yang airnya, (kira-kira ucapannya seperti ini) populer pada masa itu adalah nilai 10. 'buat apa anda menjadi ulama Jika nilai 10 ini diberikan kepada sedangkan tanah airmu masih Zainuddin maka murid Shaulatiyah dijajah'."29 lainnya tidak berhak diberikan nilai 10. Setelah dilakukan musyawarah, maka diputuskan Zainuddin diberikan nilai sepuluh dengan tanda bintang di atasnya. Hanya dua mata pelajaran yang murni bernilai sepuluh." 27

Begitu lulus Tuan Guru Kyai Haji Muhammad Zainuddin langsung diminta mengajar di Madrasah alShaulatiyah, sembari menunggu adiknya yang masih bersekolah di Mekah, beliau mengajar di Madrasah al-Shaulatiyah hanya selama dua tahun. Beliau disuruh pulang ke Lombok oleh guru kesayangannya, yaitu Syaikh Hasan Muhammad alMasysyath. "pahalamu bukan di Mekah, tapi pahalamu ada di

${ }^{27}$ Mursyidin, wawancara, Pancor, 5 Desember 2017

\section{E. Pemikiran Politik Islam Tuan Guru Kyai Haji Muhammad Zainuddin Abdul Majid}

Sepulang dari menuntut ilmu selama dua belas tahun di Tanah Suci Mekah, Tuan Guru Kyai Haji Muhammad Zainuddin Abdul Majid dipercayai oleh masyarakat untuk menjadi imam dan khatib. Selain itu, beliau sering melakukan safari dakwah ke berbagai tempat di Pulau Lombok. Setelah mempunyai reputasi di masyarakat, beliau mendirikan sebuah pesantren yang diberi nama pesantren al-Mujahidin pada tahun $1934 \mathrm{M}$. Mulanya pesantren al-Mujahidin

\footnotetext{
28 Yusuf Makmun, wawancara, Pancor, 5 Desember 2017

${ }^{29}$ Tohri, wawancara, Mataram, 20 Februari 2018
} 
menerapkan pembelajaran dengan sistem halaqah. Namun dinilai tidak efektif, sistem halaqah diganti dengan sistem klasikal, sistem klasikal ini pun mengalami banyak kendala sehingga dibentuklah sistem semi klasikal.

Berdirinya pesantren alMujahidin menimbulkan kecurigaan pemerintah Hindia Belanda, sehingga pemerintah mengirim mata-mata untuk memantau aktivitas di pesantren. Pemerintah Hindia Belanda merasa terancam dengan berdirinya pesantren. Pada suatu waktu, Tuan Guru Kyai Haji Muhammad Zainuddin Abdul Majid dipanggil untuk menghadap pemerintah seperti yang diillustrasikan oleh Tuan Guru Haji Yusuf Makmun, sebagai berikut: "untuk apa mendirikan pesantren ?" tanya pemerintah Hindia Belanda "Saya mendirikan pesantren untuk mengajar anak sasak agar mereka belajar tentang agamanya secara maksimal " jawab Tuan Guru Kyai Haji Muhammad Zainuddin Abdul Majid.

"Saya curiga anda menanam doktrin untuk melawan pemerintah"
“Kalau pemerintah wajib kami dukung, ajaran Islam mengajarkan untuk membantu, tunduk dan taat kepada pemerintah" kata Tuan Guru Kyai Haji Muhammad Zainuddin Abdul Majid. ${ }^{30}$ Meski pemerintah berkali-kali mendatangi atau memanggil Tuan Guru Kyai Haji Muhammad Zainuddin Abdul Majid untuk menghadap, diplomasi yang dilakukannya membuat pesantren al-Mujahidin tetap aman dan terhindar dari gangguan pemerintah. Maka, Tuan Guru Kyai Haji Muhammad Zainuddin Abdul Majid dengan bebas menanam doktrin kepada masyarakat dan muridmuridnya untuk melawan penjajah, bukan melawan pemerintah, sebab saat itu yang memerintah adalah penjajah.

Pesatnya perkembangan pesantren al-Mujahidin, mendorong Tuan Guru Kyai Haji Muhammad Zainuddin Abdul Majid untuk membangun sebuah madrasah sebagai lembaga pendidikan Islam di pulau Lombok. Setelah bangunan fisik madrasah dianggap selesai, Tuan Guru

30 Yusuf Makmun, wawancara, Pancor, 5 Desember 2017 
Komunike, Volume XI, No. 1, Juni 2019

Kyai Haji Muhammad Zainuddin Abdul Majid mengajukan permohonan pendirian madrasah kepada pemerintah Hindia Belanda Kontrolier Oost Lombok di Selong, Lombok Timur. Kemudian pemerintah Hindia Belanda memberikan surat izin akte pendirian madrasah pada tanggal 17 Agustus 1936 M. Satu tahun kemudian, pada tanggal 22 Agustus 1937 Madrasah Nahdlatul Wathan Diniyah Islamiyah (NWDI) diresmikan. ${ }^{31}$

\section{Kemajuan-kemajuan} yang dicapai NWDI, kemudian melahirkan gagasan untuk membangun lembaga pendidikan agama yang dikhususkan untuk perempuan. Maka pada tanggal 21 April 1943, berdiri sebuah lembaga pendidikan agama khusus perempuan yang diberi nama Madrasah Nahdlatul Banat Diniyah Islamiyah (NBDI).

Masuknya Jepang di pulau Lombok setelah mematahkan pemerintahan Hindia belanda, tidak membuat madrasah menjadi lebih baik, bahkan menambah ancaman bagi madrasah NWDI dan NBDI, selain reaksi keras dari masyarakat yang anti ..., hal 186 terhadap madrasah. Kolonial Jepang lebih sering mengawasi dan menjadikan madrasah sasaran utama kebijakan-kebijakan diskriminatif. Madrasah NWDI dan NBDI hampir saja ditutup oleh kolonial Jepang. Namun, datang surat kawat dari pemerintah Jepang di Bali yang memperbolehkan madrasah NWDI dan NBDI untuk tetap beroperasi tapi namanya diganti menjadi Sekolah Imam dan Penghulu. $^{32}$ Di sisi lain, pengajianpengajian yang dipimpin oleh Tuan Guru Kyai Haji Muhammad Zainuddin Abdul Majid dibatasi ruang geraknya dan bahkan dilarang. Inilah yang menghambat laju perkembangan madrasah NWDI dan NBDI.

Pasukan sekutu yang menyerang Jepang dengan menjatuhkan bom atom di Hiroshima dan Nagasaki, memaksa Jepang menyerah tanpa syarat. Pada tanggal 17 Agustus 1945, di depan rumah nomor 56 di Jalan Pegangsaan Timur, Soekarno dan Hatta memproklamasikan kemerdekaan Indonesia. Adam Malik, telah mengusahakan disiarkannya 
berita mengenai berdirinya negara merdeka Republik Indonesia melalui radio. Proklamasi kemerdekaan berarti tidak hanya berakhirnya penjajahan Jepang, tetapi juga penjajahan Belanda. $^{33}$

Kabar kemerdekaan Republik Indonesia 17 Agustus 1945, terdengar di Lombok sekitar bulan Oktober. Setelah mengetahui kemerdekaan Negara Republik Indonesia, Tuan Guru Kyai Haji Muhammad Zainuddin Abdul Madjid, tidak lantas berdiam diri, melainkan terus mengawal Kemerdekaan. Pasukan Australia yang ditugaskan Sekutu mendarat di Ampenan 30 November 1945, dan mulai beroperasi di Lombok. Kedatangan tentara Australia yang tugas utamanya melucuti senjata Jepang, tidak membawa perubahan lebih baik di Lombok. Justru memuluskan NICA (Netherlands Indies Civil Administrations) masuk ke Sunda Kecil pada bulan Maret 1946. Pasukan NICA dalam waktu singkat menguasai daerah-daerah yang diduduki pasukan

\footnotetext{
${ }^{33}$ Kapitsa M.S dan Maletin N.P, Soekarno; Biografi Politik, terj. B. Soegiharto, (Bandung: Ultimus, 2009), Hal. 107.
}

Australia, diganti dengan pasukan Belanda dan bekas pegawai pamong praja, seperti residen, asisten residen, kontrolir atau jabatan lainnya, bahkan mendirikan tangsi-tangsi militer.

Tuan Guru Kyai Haji Muhammad Zainuddin Abdul Majid membuat suatu gerakan bawah tanah yang disebut gerakan al-Mujahidin yang dipimpin oleh Tuan Guru Haji Muhammad Faishal dan Tuan Guru Haji Ahmad Rifa'i. Gerakan ini bergabung bersama gerakan Banteng Hitam, gerakan Bambu Runcing, BKR, API di Pulau Lombok menyerbu markas NICA di Selong pada tanggal 7 Juni 1946 dan mempertahankan kemerdekaan serta keutuhan bangsa Indonesia ${ }^{34}$. Akibat dari pertempuran tersebut Tuan Guru Haji Muhammad Faishal, sayyid muhammad sholeh dan Abdullah gugur di medan tempur. Sedangkan Tuan Guru Haji Ahmad Rifa'i dan Muhammad Yusi Muhsin tertangkap dan ditahan di Bali. Bahkan, Tuan Guru Haji Ahmad Rifa'i pernah dibuang ke Ambon.

\footnotetext{
${ }^{34}$ Masnun, Tuan Guru KH Muhammad
} Zainuddin Abdul Majid; Gagasan dan Gerakan Pembaharuan Islam Di Nusa Tenggara Barat (Jakarta: Pustaka al-Miqdad, 2007), hal. 27. 
Komunike, Volume XI, No. 1, Juni 2019

Keutuhan kemerdakaan

Indonesia di Pulau Lombok yang dipelopori oleh Tuan Guru Kyai Haji Muhammad Zainuddin Abdul Majid menjadikannya Amirul Hajji ke Mekah dari Negara Indonesia Timur (NIT) tahun 1947, menjadi anggota delegasi NIT ke Saudi Arabia tahun 1948-1949, menjadi konsulat Nahdlatul Ulama (NU) sunda kecil tahun 1950, menjadi Ketua Badan Penasehat Partai Masyumi daerah Lombok tahun 1952.

Di tahun 1953, Tuan Guru Kyai Haji Muhammad Zainuddin Abdul Majid mendirikan Organisasi Nahdlatul Wathan (NW) pada tanggal 1 Maret 1953 di Pancor Lombok Timur. Sebuah organisasi sosial kemasyarakatan yang bergerak dalam bidang pendidikan, sosial dan dakwah Islamiyah. Berdirinya organisai NW dilatarbelakangi karena. Pertama, pertumbuhan dan perkembangan cabang-cabang Madrasah NWDI dan NBDI, majlis dakwah dan majlis ta'lim yang begitu pesat. Kedua, karena desakan petinggi partai Masyumi yang meminta untuk membentuk sebuah organisasi massa sebagai basis suara partai Masyumi, sebab saat itu NU akan keluar dari Masyumi. ${ }^{35}$

Tohri mengungkapkan: "maulana syeikh adalah sosok yang selalu mengikuti perkembangan zaman. Ketika perlu mendirikan madrasah, maka beliau bangun madrasah, ketika perlu dibangun sekolah formal, maka beliau bangun, begitu juga ketika dirasa perlu dibangun perguruan tinggi, beliau bangun"

Selain membangun pondok pesantren, Tuan Guru Kyai Haji Muhammad Zainuddin Abdul Majid juga membangun sekolah formal dan perguruan tinggi Islam, untuk mencerdaskan masyarakat Lombok. Sekolah dan perguruan tinggi yang beliau bangun antara lain: Tahun 1964 mendirikan Akademik Paedagogik Nahdlatul Wathan, tahun 1965 mendirikan Ma'had Daril Quran wal Hadits al-Majidiyah Asy-Syafi'iyah Nahdlatul Wathan, Tahun 1974 mendirikan Ma'had lil Banat, Tahun

35 "Biografi TGKH. Muhammad Zainuddin Abdul Majid Sebagai Pahlawan Nasional Republik Indonesia; Dalam Pendidikan, Politik dan

Transformasi Sosial Masyarakat Indonesia", dalam Naskah Akademik Pengusulan Gelar Pahlawan

Nasional Tuan Guru Kyai Haji Muhammad Zainuddin Abdul Madjid, 2017, hal. 50. 
Komunike, Volume XI, No. 1, Juni 2019

197

mendirikan Unversitas

membentuk partai Masyumi. maka di HAMZANWADI, Tahun 1977 menjadi tahun 1949, Tuan Guru Kyai Haji rektor Unversitas HAMZANWADI, Muhammad Zainuddin Abdul Majid Tahun 1977 mendirikan Fakultas bersama Saleh Sungkar mendirikan Tarbiyah HAMZANWADI, Tahun 1978 mendirikan STKIP HAMZANWADI, cabang partai Masyumi di Lombok. ${ }^{37}$

Tahun 1950, Tuan Guru Kyai Haji Tahun 1978 mendirikan Sekolah Tinggi Muhammad Zainuddin Abdul Majid Ilmu Syari'ah (STIS) HAMZANWADI, diangkat sebagai Konsulat NU Sunda Tahun 1982 mendirikan Yayasan Kecil menggantikan Syekh Abdul Pendidikan HAMZANWADI, Tahun Manan. ${ }^{38}$ Pada tahun 1952, Tuan Guru 1987 mendirikan Sekolah Tinggi Ilmu Kyai Haji Muhammad Zainuddin Abdul Dakwah (STID) HAMZANWADI, Tahun Majid diangkat menjadi Ketua Badan 1987 mendirikan Universitas Nahdlatul Wathan, Tahun 1987 mendirikan Sekolah Tinggi Ilmu Hukum (STIH) HAMZANWADI.

Saleh Sungkar mendirikan organisasi Persatuan Umat Islam Lombok (PUIL) Pada tahun 1947, bersama-sama Tuan Guru Kyai Haji Muhammad Zainuddin Abdul Majid. ${ }^{36}$ Lalu PUIL menggabungkan diri ke dalam Organisasi Nahdlatul Ulama (NU) cabang Lombok yang dibawa oleh Syeikh Abdul Manan. NU pada waktu itu berafiliasi dengan beberapa organisasi Islam bergabung dan

${ }^{36}$ Burhan D. Magenda, “ Dinamika Peranan Politik Keturunan Arab di Tingkat Lokal", Antropologi Indonesia, Vol. 29, Nomor 2, 2005, hal. 187.

Penasihat Partai Masyumi untuk daerah Lombok.

Pada bulan Oktober Tahun 1952 Nahdlatul Ulama (NU) yang memiliki basis terbesar di daerah Jawa Timur dan Jawa Tengah keluar dari partai Masyumi dan menyatakan diri sebagai partai politik. ${ }^{39}$ Penarikan diri NU dari Masyumi menimbulkan dampak yang luar biasa di dalam tubuh Masyumi. Ada beberapa kekecewaan NU terhadap Masyumi. Pertama, NU tidak menyetujui perubahan rumusan

\footnotetext{
${ }^{37}$ Ibid.,

${ }^{38}$ Abdurrahman Wahid, "Tuan Guru Haji Lalu Muhammad Faisal Dimata Gusdur", dalam http://www.tabayyunews.com/2016/10/tuan-guruhaji-lalu-muhammad-faisal.html, diakses tanggal 5 Desember 2017, pukul 03.00.

39 Masykuri abdillah, Demokrasi Di Persimpangan..., hal. 35 .
} 
Komunike, Volume XI, No. 1, Juni 2019

Majelis Syura dalam AD/ART Masyumi pada muktamar ke-14 tahun 1949 di Yogyakarta, kedudukan NU hanya sebagai badan penasehat, organisasi tidak menyediakan tempat yang layak terhadap para ulama. Kedua, kalangan NU menginginkan posisi Menteri Agama dalam kabinet, namun usul $\mathrm{KH}$. Wahab Hasbullah tidak terpenuhi, karena menteri agama ketika itu adalah KH. Fakih Usman dari Muhammadiyah. Kalangan ini melihat kepemimpinan dalam partai Masyumi tidak memberikan tempat yang layak terhadap kyai dan bahkan hanya sebagai pelengkap saja. ${ }^{40}$

Keluarnya NU dari partai Masyumi, mengubah struktur kepengurusan di dalam tubuh NU. Tuan Guru Kyai Haji Muhammad Zainuddin Abdul Majid memilih tetap berada di partai Masyumi. Sebelum NU menyatakan diri keluar, para petinggi Partai Masyumi di Jawa sudah melihat gelagat Nahdlatul Ulama yang mulai menyatakan ketidakpuasan, jika Nahdlatul Ulama keluar dari Masyumi, maka dikhawatirkan massa pendukung hal. 168-169. yang ada di Lombok juga akan ikut tercerai-berai, sehingga massa pendukung yang sebagian besar berada di bawah pengaruh Tuan Guru Kyai Haji Muhammad Zainuddin Abdul Madjid yang menjadi epicentrum politik, harus segera diikat dalam organisasi selain NU, untuk menjadi anggota istimewa. ${ }^{41}$ maka pada tanggal 1 Maret 1953, Tuan Guru Kyai Haji Muhammad Zainuddin Abdul Majid mendirikan organisasi Nahdlatul Wathan (NW). Beliau menyatakan NW menganut "politik bebas". Namun, hanya dari tahun 1953-1955. Di tahun 1955 Tuan Guru Kyai Haji Muhammad Zainuddin Abdul Majid memasukkan Nahdlatul Wathan (NW) ke dalam partai Masyumi. "Masyumi merupakan konsensus ulama, beliau taat pada konsensus tersebut". ${ }^{42}$ Masuknya NW menambah kekuatan partai Masyumi, selain dari organisasi Islam lokal dan Nasional, juga masih banyaknya orang NU, dalam bidang politik berkiblat ke

41 "Biografi TGKH. Muhammad Zainuddin Abdul Majid Sebagai Pahlawan Nasional Republik Indonesia; Dalam Pendidikan, Politik dan Transformasi Sosial Masyarakat Indonesia", dalam Naskah Akademik Pengusulan Gelar Pahlawan Nasional Tuan Guru Kyai Haji Muhammad Zainuddin Abdul Madjid, 2017, hal. 50.

${ }^{42}$ Tohri, wawancara, januari 2018. 
partai Masyumi, dikarenakan pelajaran, bukan hanya untuk muridberpegang pada semacam fatwa $\mathrm{KH}$. murid beliau tetapi juga untuk Hasyim As'ari bahwa Masyumi satu- masyarakat Lombok, bahwa bukan satunya partai Islam Indonesia yang suatu yang haram seorang ulama itu sah. ${ }^{43}$ berpolitik, sebab pada saat itu tuan

Berafiliasinya NW dengan partai guru yang masuk ke dunia politik Masyumi membuat Tuan Guru Kyai Haji Muhammad Zainuddin Abdul masih sangat dianggap tabu oleh Majid diangkat menjadi anggota masyarakat Lombok". ${ }^{4}$

Konstituante periode 1955-1959, dari Selain ikut dalam hasil Pemilihan Umum (Pemilu) pertama yang dilaksanakan pada tahun 1955.

memperjuangkan asas dasar negara, terpilihnya beliau menjadi anggota Konstituante juga untuk mengakomodir aliran kepercayaan Selama menjadi anggota yang ada di Lombok, TGH Abdul konstituante, Tuan Guru Kyai Haji Hamid, pengasuh yayasan al-Amin Muhammad Zainuddin Abdul Madjid yang merupakan tokoh NU dan aktif ikut bersidang dan berdinamika, Mantan DPR Kota Mataram berkantor di Bandung, Jawa Barat. mengungkapkan:

Berbagai hal terkait sidang serta

"Maulana Syeikh mengakomodir pengalamannya selama menjadi aliran kepercayaan, yang berada di Anggota Dewan Konstituante, luar agama yang sudah ditetapkan seringkali diceritakan kepada para oleh negara, agar tidak digunakan muridnya, sebagai bahan sebagai senjata oleh bangsa lain. pembelajaran.

Ustadz Mursyidin mengungkapkan: "maulana syeikh berpolitik untuk memberikan

${ }^{43}$ Nurcholis Madjid, Dialog Keterbukaan; Artikulasi Nilai Islam Dalam Wacana Sosial Politik Kontemporer, (Jakarta: Paramadina, 1998), hal. 161.
Seperti ketika disumpah, maulana syeikh menggunakan 'aku berjanji' bukan 'aku bersumpah', sebab menurut beliau janji lebih kuat daripada sumpah, kalau sumpah kita ${ }^{44}$ Mursyidin, wawancara, Pancor, 5
Desember 2017 
Komunike, Volume XI, No. 1, Juni 2019

langgar, masih bisa dibayar, tapi kalua janji tidak bisa kita bayar, jadi janji itu lebih kuat daripada sumpah, padahal yang biasa menggunakan 'aku berjanji' adalah aliran kepercayaan." ${ }^{45}$

Berbagai manuver yang dilakukan petinggi Partai Masyumi ini tidak sesuai lagi dengan prinsip dalam Masyumi. TGH Abdul Hafidz Sulaiman bersama Tuan Guru Kyai Haji Muhammad Zainuddin Abdul Madjid melayangkan surat kritik pada $12 \mathrm{Mei}$ 1959 yang judulnya "Risalah Bandung". Isinya, beliau tidak menerima perlakuan tidak adil/tidak aman terhadap anggota masyumi yang kebanyakan bermazhab syafi'i, ahlus sunnah wal jamaah, bahwa yang duduk di pimpinan partai masyumi yang mengaku diri bermazhab telah berupaya memboikot, menghantam dan merong-rong mazhab yang telah menjadi jiwa perjuangan mereka. Kritik ini karena prilaku pengurus Masyumi di lombok yang telah mempolitisasi kamu bermazhab syafi'i. Ada juga yang telah membuat yayasan yang hanya dibungkus nama Islam, tetapi diisi oleh

45 Abdul hamid, wawancara, Mataram, 2 Februari 2018. orang-orang yang tidak bertanggung jawab. ${ }^{46}$ kekecewaan terhadap partai Islam juga tersirat di dalam wasiat beliau:

$$
\text { Ajaibnya terkadang di partai }
$$

Islam Berpura-pura membela Islam Aktif keliling siang dan malam Membela diri melupakan Islam ${ }^{47}$

Sistem politik Indonesia yang menganut demokrasi liberal dari tahun 1949-1959, sehingga partai politik bebas menentukan ideologi negara Republik Indonesia, maka muncullah gagasan Islam sebagai ideologi bernegara dari Muhammad Natsir. Di dalam sidang Majelis Konstituante pada 10 november 1956, Seluruh partai Islam menyetujui gagasan tersebut, akan tetapi partai Islam kalah suara dengan pendukung pancasila sebagai ideologi bernegara. ${ }^{48}$

$\begin{array}{ccc} & \text { Presiden Soekarno didukung } \\ \text { oleh angkatan bersenjata }\end{array}$
mengeluarkan Dekrit 5 Juli 1959, tentang "kembali keundang-undang

${ }^{46}$ Patompo Adnan, TGH Abdul Hafidz Sulaiman 1898-1983; Ilmu Bening Sebening Hati Guru-Sebuah Biografi, (Lombok Barat: mujahid press, 2013). Hal. 88

47 Tuan Guru Haji Muhammad Zainuddin Abdul Majid, Wasiat..., hal. 55.

${ }^{48}$ Masykuri abdillah, Demokrasi Di Persimpangan..., hal. 35 
Komunike, Volume XI, No. 1, Juni 2019

dasar 1945". ${ }^{49}$ Di tahun yang sama Presiden Soekarno juga merubah sistem politik Indonesia menjadi demokrasi terpimpin. Beberapa pemimpin dari partai Masyumi kecewa dengan presiden Soekarno yang dianggap otoriter, hingga melakukan perlawanan. Akibatnya, beberapa dari pemimpin partai Masyumi ditangkap dan partai Masyumi menjadi partai terlarang pada 30 September 1960. Di lain pihak, Soekarno memberikan kesempatan yang baik kepada partai Komunis dan mengumumkan kebijakan tentang NASAKOM (Nasionalis-Agama-Komunis). ${ }^{50}$

Semenjak partai Masyumi dilarang oleh pemerintah, Tuan Guru Kyai Haji Muhammad Zainuddin Abdul Majid tidak terlalu aktif berpolitik. Meski beliau mendukung berdirinya partai Parmusi di Lombok, yang merupakan duplikasi dari partai Masyumi. Namun, beliau tidak dapat berperan aktif menjadi anggota. Ini disebabkan oleh tidak terakomodirnya aspirasi NW.

Soeharto menerima Surat Perintah 11 Maret, dia melarang PKI

\footnotetext{
${ }^{49}$ Ibid,. Hal. 37.

${ }^{50}$ Ibid., Hal. 38.
}

dan organisasi-organisasi massanya dan kemudian dikuatkan dengan ketetapan MPRS tahun 1966. Tanggal 11 Maret 1966 merupakan titik awal pemerintahan Orde Baru. Banyak pemimpin Islam berpikir, bahwa hancurnya PKI merupakan kemenangan bagi Islam, selanjutnya Islam akan memperoleh peran penting di kalangan masyarakat dan akan menjadi kekuatan politik di masa Orde Baru. Pemimpin partai Masyumi meminta pemerintah Orde Baru untuk merehabilitas partai Masyumi. Tetapi permintaan tersebut ditolak, bahkan melarang mantan-mantan pemimpin partai Masyumi kembali berpolitik. Tidak hanya itu, pemerintah Orde Baru bahkan menyederhanakan partai politik menjadi tiga: Golkar sebagai partai pemerintah, PPP sebagai partai umat Islam dan PDI sebagai partai nasionalis. Penyerderhanaan ini agar mempermudah pemerintah Orde baru untuk mengontrol partai politik.

Tuan Guru Kyai Haji Muhammad Zainuddin Abdul Majid mengganti haluan politiknya dengan berafiliasi ke partai Golkar pada 28 September 
Komunike, Volume XI, No. 1, Juni 2019

1970. Ada beberapa alasan Tuan Guru Kyai Haji Muhammad Zainuddin Abdul Majid memilih berafiliasi dengan partai Golkar.

Berafiliasinya ke partai Golkar untuk menyelamatkan NW dari kediktator-an Pemerintah, sebab banyak pondok pesantren yang ditutup karena tidak sejalan dengan pemerintah Orde Baru.Tuan Guru Haji Yusuf Makmun menjelaskan maksud Tuan Guru Kyai Haji Muhammad Zainuddin Abdul Majid berafiliasi dengan Golkar:

"Maulana Syeikh (panggilan

Tuan Guru Kyai Haji Muhammad Zainuddin Abdul Majid) melihat kewenangan hak prerogatif atau kekuasaan yang sangat kental kepada pemerintah saat itu, maka tidak ada yang paling pas kecuali bersama pemerintah, beliau mengajak semua warga NW dan simpatisan untuk menyalurkan apresiasi politiknya lewat Golkar, sebagai buktinya beliau menanam pohon beringin, ikut dengan pemerintah untuk meneruskan perjuangan dan menyelamatkan madrasah agar tidak ditutup." ${ }^{51}$ Senada dengan yang diungkapkan oleh TGH Abdul Hamid:

"pondok pesantren yang berkonfrontasi dengan pemerintahan, tidak mendapat bantuan dana, seperti NU misalnya yang ketika itu, tidak berani mencantumkan nama di depan lemaba pendidikannya, masuknya maulana syaikh ke Golkar untuk memback up pondok pesantren tersebut. Selain itu, untuk mengimbangi pahampaham aliran kiri dan kanan agar mudah dinetralisir." 52

Sedangkan Dr. Khirjan Nehdi, akademisi NW dan WR II Universitas Hamzanwadi mengungkapkan, berafiliasinya NW ke partai pemerintah (Golkar) agar dapat mengakomodir aspirasi masyarakat NW. dan juga sebagai rasa terima kasih karena telah menumpas PKI:

"keberadaan beliau di Golkar tidak lepas dari sejarah kita beragama Islam, tidak ada yang dapat memastikan Orde Baru yang di

\footnotetext{
51 Yusuf Makmun, wawancara, pancor, 5 Desember 2017.

52 Abdul hamid, wawancara, 2 Februari 2018
} 
Komunike, Volume XI, No. 1, Juni 2019

dalamnya ada Golkar, begitupun sebaliknya. Artinya bahwa dalam kondisi Orde Baru yang di dalamnya ada Golkar maka keberislaman ini tumbuh berkembang dengan baik, aman. Itu yang saya maksud dengan dan/atau tanpa Golkar. Dengan Orde Baru yang ada Golkar. Keberagaman kita menjadi baik, harmoni, kalau dihubungkan dengan konteks kebhinnekaan, Orde Baru yang mengusung konsep toleransi. Maka dari itu, salah satu cara berterima kasih kepada Soeharto, yang dianalogikan sejajar dengan Orde Baru dan Golkar, dengan cara mendukung partai Golkar. Karena kalau tidak, mungkin bisa jadi komunis yang berkembang. Jadi dukungan tersebut sebagai rasa terima kasih kepada pemerintah Orde Baru karena telah menumpas PKI. Meski terjadi perdebatan panjang. ${ }^{153}$

Sedangkan menurut Dr. Tohri, akademisi NW dan dosen UIN Mataram mengungkapkan: "Maulana syeikh taat pada pemerintah, memilih Golkar merupakan ketaatan kepada

\footnotetext{
${ }^{53}$ Khirjan Nehdi, wawancara, Pancor, 6
} Desember 2017 pemerintah. Selain itu, Partai yang tidak pernah terlibat dalam Nasakom adalah Golkar". ${ }^{54}$

Kedekatan Tuan Guru Kyai Haji Muhammad Zainuddin Abdul Majid dengan pemerintah menjadikan beliau sebagai anggota dewan pertimbangan MUI pusat dari tahun 1971-1982. Begitu juga Dalam Pemilihan Umum (Pemilu) tahun 1971 dan 1977, beliau terpilih menjadi anggota Majelis Permusyawaratan Rakyat (MPR) RI dari partai Golkar. Selama berafiliasi dengan partai Golkar, Tuan Guru Kyai Haji Muhammad Zainuddin Abdul Majid banyak mempromosikan kaderkader terbaik NW untuk duduk di dalam kursi pemerintahan.

TGH. Muhlis Ibrahim, pimpinan pondok pesantren Islahuddinny menerangkan:

"Tuan Guru Zainuddin Abdul Majid, banyak mempromosikan kaderkader terbaik NW untuk duduk di pemerintahan, seperti Tafaul,SH. H. Amnan,SH. Dan lain-lain, supaya menguasai upaya pengembangan dakwah, juga untuk ikut serta dalam

\footnotetext{
54 Tohri, wawancara, Mataram 20 Februari 2018
} 
Komunike, Volume XI, No. 1, Juni 2019

memberikan distribusi pemikiran masa yang rampung ditulis pada 1 misalnya, untuk mengesahkan undang- maret 1970 beliau menulis:

undang minuman keras, agar tidak "aduh sayang!Pintu NW terbuka menjadi konsumsi masyarakat luas, lama Bagi anakku yang ingin bersama semuanya dilakukan untuk Mari bersama selama-lama Jangan menyelamatkan umat. Beliau juga kembali ke ORDE LAMA"56 menjadi orang terdepan dalam 'aduh sayang! Ta' ada artinya menjalankan dan menyukseskan organisasi Kalau ta' dito'ati Itu program pemerintah seperti Gogo namanya ber NAPSI-NAPSI Ber NAPSURancah (GORA), imunisasi, dan NAPSU membakar diri"57 program Keluarga Berencana (KB). Dalam Pemilu keempat tahun Karena beliau sangat taat kepada 1982 beliau terpilih kembali menjadi pemerintah." 55

Bergitu juga dengan apa yang anggota MPR RI. Namun dari utusan fraksi daerah, sebab dalam pemilihan terjadi di dalam tubuh NW ketika Tuan Guru Kyai Haji Muhammad Zainuddin Abdul Majid memilih untuk berafiliasi dengan partai Golkar terjadi konflik internal, sebab beberapa pengurus NW memilih PPP sebagai kendaraan politik mereka, akhirnya beberapa pengurus yang tidak sejalan dengan organisasi diisingkarkan dari umum keempat Tuan Guru Kyai Haji Muhammad Zainuddin Abdul Majid tidak lagi memobilisator partai Golkar dan melakukan politik diam atau gerakan tutup mulut. kekecewaan beliau terhadap Golkar yang sangat otoriter dan pejabat-pejabat di pemerintahan yang dirasa tidak lagi adil dan tidak sesuai janji. Seperti yang kepengurusan. beliau mengajak semua murid serta simpatisan untuk memilih Golkar, dianalogikan seperti sholat berjamaah. Di dalam wasiat renungan

${ }^{55}$ Muhlis Ibrahim, wawancara, Kediri 10 Februari 2018. diungkapkan oleh Dr. Tohri, "bahwa Golkar banyak mengingkari janjijanjinya" ${ }^{58}$. Hal senada juga

\footnotetext{
${ }^{56}$ Tuan Guru Haji Muhammad Zainuddin Abdul Majid, Wasiat..., hal. 89.

${ }^{57}$ Ibid.,92 2018

${ }^{58}$ Tohri, wawancara, mataram 20 Februari
} 
Komunike, Volume XI, No. 1, Juni 2019

diungkapkan oleh Tuan Guru Haji Yusuf Makmun:

"di pemilu keempat, Maulana Syeikh tidak lagi mengusung Golkar sebagai kendaraan politiknya, karena tidak sesuai dengan janji-janji yang diucapkan dulu, ditambah dengan dana yang harusnya untuk NW dipotong oleh pemerintah, inilah yang menambah kekecawaan beliau terhadap Golkar." 59

Dengan melakukan politik diam, suara Partai Golkar di Lombok turun drastis meski masih unggul dari partai yang lain. Tuan Guru Kyai Haji Muhammad Zainuddin Abdul Majid didatangi oleh petugas partai Golkar perihal tersebut. Namun beliau melakukan diplomasi dengan mengatakan: "saya tidak pernah keluar dari Golkar, kalau saya keluar dari Golkar pasti ada surat tertulis". ${ }^{60}$

Di sisi lain TGH Abdul Hamid menceritakan ketika bertemu dengan Tuan Guru Kyai Haji Muhammad Zainuddin Abdul Majid untuk menyampaikan agar tidak keluar dari Golkar:

${ }^{59}$ Yusuf Makmun, wawancara, Pancor, 5 Desember 2017

${ }^{60}$ Yusuf Makmun, wawancara, Pancor, 5 Desember 2017 "saya bawa nama Gobel, ketika mengunjungi maulana syeikh, beliau ingin keluar dari golkar bersama Raja Bima, beliau sudah sangat kecewa dengan Golkar, bahasa kasarnya, Golkar sudah tidak bisa dilslamkan, saya sampaikan kepada beliau agar tetap di Golkar, bisa menguntungkan tapi kalau keluar dari Golkar, sangat berbahaya pengaruh maulana syeikh akan hilang, terbukti ketika pemilu di datangkan gubernur sulawesi selatan, Muhammad Lamo, jadilah komputer dalam pemilu, dibuka pemilihan jam 8 diumumkan jam 9 secara nasional” 61 Pindahnya Tuan Guru Kyai Haji Muhammad Zainuddin Abdul Majid dari Golkar ke PPP juga atas permintaan dari syeikh Ismail Bin Zein Usman al-Yamani. maka beliau mengarahkan masyarakat Lombok untuk memilih PPP. Seperti cerita yang diilustrasikan oleh TGH Turmudzi Badaruddin, pimpinan pondok pesantren Qomarul Huda, ketika Tuan Guru Kyai Haji Muhammad Zainuddin Abdul Majid diminta oleh Syeikh Ismail Bin Zein Usman al-Yamani untuk

${ }^{61}$ Abdul Hamid, wawancara, Mataram 11 Februari 2018 
Komunike, Volume XI, No. 1, Juni 2019

pindah ke PPP, serta cara beliau mengarahkan masyarakat Lombok untuk memilih PPP:

"saat itu saya berada di Mekah dan ditanya oleh guru saya yaitu Syeikh Ismail bin zein usman al Yamani"

'Turmduzi kamu ikut mana ?' tanya Syeikh Ismail 'saya ikut PPP' jawab TGH Turmudzi 'Syeikh Zainuddin ikut mana ?' 'beliau ikut pemerintah, ikut Golkar' 'kalau begitu besok saya ke Lombok'

"ketika Syeikh Ismail berkunjung ke Lombok untuk mengunjungi Tuan Guru Pancor (Zainuddin), saya ikut mengiri Syeikh Ismail ke Pancor bersama Tuan Guru-Tuan Guru yang lain"

Syeikh Ismail meminta ke Tuan Guru Pancor 'kalau bisa Syeikh Zainuddin untuk memilih PPP'

'Apa alasan saya kalau memilih PPP, saya sudah mengerahkan NW berserta Banom-Banomnya untuk memilih Golkar, apa kata orang' jawab Tuan Guru Kyai Haji Muhammad Zainuddin Abdul Majid
'Rasullah saja bisa mengubah arah kiblatnya dari Baitul Muqaddis ke Ka'bah' kata Syeikh Ismail

'Kalau demikian, baik saya akan pilih PPP'

"ketika Tuan Guru Kyai Haji Muhammad Zainuddin Abdul Majid berceramah di masjid Bagu, beliau mengatakan" 'jama'ah, jangan lagi menghadap ke pohon beringin, banyak setannya, mari kita sama-sama kembali menghadap ke Ka'bah'.

“Kemudian ketika beliau ceramah di Puyung beliau mengatakan"

'hai jama'ah, sekarang kita pergi ke Mekah mengerjakan haji, sembelih sapi itu, tebang pohon kayu itu, kita bikin gawe yang besar'62.

Untuk meredam konflik di dalam tubuh NW ketika Tuan Guru Kyai Haji Muhammad Zainuddin Abdul Majid berpindah haluan Politik maka lahirlah gagasan agar NW kembali ke khittah, gagasan tersebut disepakati dan disetujui pada muktamar ke-VII tanggal 24-25 Februari 1986 di Pancor. Dengan

${ }^{62}$ Turmudzi Badaruddin, wawancara, Bagu, 10 Januari 2018. 
kembalinya NW ke khittah maka murid atau jama'ah dibebaskan dalam memilih haluan politiknya.

\section{Kesimpulan}

Di kalangan ulama dan intelektual muslim di dunia terdapat tiga pandangan hubungan antara ajaran islam dengan masalah kenegaraan. Pertama, adalah kelompok konservatif, yang tetap mempertahankan integritas antara Islam dan negara, karena menurut mereka, Islam telah lengkap mengatur sistem kemasyarakatan. Kelompok ini terdiri dari (a) tradisionalis, yakni mereka yang tetap mempertahankan tradisi praktik dan pemikiran politik Islam klasik/pertengahan, seperti Rasyid Ridha, dan (b) fundamentalis, yakni mereka yang ingin melakukan reformasi sistem sosial dengan kembali kepada Islam secara total dan menolak sistem yang dibuat manusia, seperti Sayyid Qutub dan Abu al-A'la al-Maududi dan Hasan Tarabi. Kedua, adalah kelompok modernis, yang berpendapat bahwa Islam mengatur masalah keduniaan (kemasyarakatan) hanya secara dasar-dasarnya saja, adapun secara tehnis bisa mengadopsi sistem lain, yang dalam hal ini adalah sistem barat yang sudah menunjukkan kelebihannya. Di antara tokoh kelompok ini adalah Muhammad Abduh, Husein Haikal, dan Muhammad Asad. Ketiga, yang memisahkan antara Islam dengan negara, karena menurut kelompok ini Islam, seperti agamaagama lainnya, tidak mengatur masalah keduniaan, sebagaimana praktik kenegaraan yang terdapat di barat. Di antara tokoh aliran ini adalah Ali Abdurraziq dan Thaha Husein.

Sebagaiman aktivitas politik Tuan Guru Kyai Haji Muhammad Zainuddin Abdul Majid akan terlihat jelas pasca kemerdekan dengan mengikuti partai politik dan menentukan arah bangsa Indonesia dengan mewakili kaum muslimin di Pulau Lombok. Karir politik Tuan Guru Kyai Haji Muhammad Zainuddin Abdul Majid dimulai sejak diangkat sebagai Konsulat Nahdlatul Ulama (NU) Sunda Kecil pada tahun 1950. Pada tahun 1952 beliau diangkat menjadi Ketua Badan 
Komunike, Volume XI, No. 1, Juni 2019

Penasihat Partai Masyumi untuk daerah Lombok, ini disebabkan pada waktu itu Nahdlatul Ulama dan beberapa ormas lainnya tergabung dalam partai Masyumi.

\section{Daftar Pustaka}

Afifuddin Adnan, Diktat Pelajaran KeNW-an, (Pancor: Biro Dakwah Yayasan Pendidikan Hamzanwadi, 1983)

Alfons Van Der Kraan, Lombok: Penaklukan, Penjajahan, dan Keterbelakangan 1870-1940, (Yogyakarta: Lengge, 2009)

Azyumardi Azra, Renaisanse Islam Asia

Tenggara, (Bandung: Remaja Rosda Karya, 1999)

Biografi TGKH. Muhammad Zainuddin Abdul Majid Sebagai Pahlawan Nasional Republik Indonesia; Dalam Pendidikan, Politik dan Transformasi Sosial Masyarakat Indonesia", dalam Naskah Akademik Pengusulan Gelar Pahlawan Nasional Tuan Guru Kyai Haji Muhammad Zainuddin Abdul Madjid, 2017.

Burhan D. Magenda, " Dinamika Peranan Politik Keturunan Arab di Tingkat Lokal", Antropologi Indonesia, Vol. 29, Nomor 2, 2005 Kapitsa M.S dan Maletin N.P, Soekarno; Biografi Politik, terj. B.
Soegiharto, (Bandung: Ultimus, 2009).

Mahmud Yunus, Sejarah Pendidikan Islam di Indonesia, (Jakarta: Hidakarya Agung, 1996).

Masykuri Abdillah "Negara Ideal Menurut Islam dan Implementasinya Pada Masa Kini" dalam Komaruddin Hidayat (ed), Islam, Negara,\& Civil Society, (Jakarta: Paramadina, 2005)

Masykuri Abdillah, Demokrasi di Persimpangan Makna; Respons Intelektual Muslim Indonesia Terhadap Konsep Demokrasi (1966-1993), terj. Wahib wahab, cet. Ke-2, ( Yogyakarta: Tiara Wacana Yogya, 2004).

Masnun, Tuan Guru KH Muhammad Zainuddin Abdul Majid; Gagasan dan Gerakan Pembaharuan Islam di Nusa Tenggara Barat (Jakarta: Pustaka al-Miqdad, 2007).

Mohammad Noor, dkk, Visi Kebangsaan Religus; Refleksi Pemikiran dan Perjuangan TGKH Muhammad Zainuddin Abdul Majid 1904-1997 (Jakarta: Logos Wacana IImu, 2004).

Nurcholis Madjid, Dialog Keterbukaan; Artikulasi Nilai Islam Dalam Wacana Sosial Politik Kontemporer, (Jakarta: Paramadina, 1998).

Nurcholish Madjid, Islam, Kemoderenan, dan Keindonesiaan, cet. Ke-6, (Bandung: Mizan,1994). 
Patompo Adnan, TGH Abdul Hafidz Sulaiman 1898-1983; Ilmu Bening Sebening Hati Guru-Sebuah Biografi, (Lombok Barat: Mujahid Press, 2013)

Sahal Mahfudh, Nuansa Fiqih Sosial, (Yogyakarta: LKiS, 2004)

Sukron Kamil, Pemikiran Politik Islam Tematik; Agama Dan Negara, Demokrasi, civil Society, Syariah dan HAM, Fundamentalisisme, dan Antikorupsi, (Jakarta: Kencana Prenada Media Gorup, 2004).

Syarifuddin Jurdi, Pemikiran Politik Islam di Indonesia: Pertautan Negara, Khilafah, Masyarakat Madani dan Demokrasi (Yogyakqarta: Pustaka Pelajar, 2008)

Tuan Turu Haji Muhammad Zainuddin Abdul Majid, Wasiat Renungan Masa Pengalaman Baru, (Lombok Timur: Pengurus Besar Nahdlatul Wathan, 2002) 